\title{
Outsourcing Practices In Malaysia: A SWOT Analysis On The ICT Industry
}

\author{
Magiswary Dorasamy, (E-mail: magiswary@mail.utar.edu.my), Universiti Tunku Abdul Rahman, Malaysia \\ Murali Raman, (E-mail: musumi_sai@yahoo.com), Monash University, Malaysia \\ Maniam Kaliannan, (E-mail: maniam@salam.uitm.edu.my), Universiti Teknologi MARA, Malaysia
}

\begin{abstract}
In the last decade, outsourcing has emerged as an important tool for enabling business around the world to gain full benefit. As Malaysia develops, the businesses must keep pace with changes that are occurring. Outsourcing initiatives are intended to increase the efficiency and effectiveness of the business processes as well as IT performance. The rethinking of business strategies to develop and exploit core competencies, set the outsourcing bandwagon rolling. It seeks to improve the quality, cost efficiency and seize of competitive advantage. This paper discusses the potential of Malaysia as a global player for ICT outsourcing. The paper focuses on SWOT analysis of ICT outsourcing in Malaysia. This paper identifies current situations in Malaysia and discuss further with the analysis on strength, weaknesses, opportunity and threats which will give effect to the businesses and society at large. No significant study has been carried out on analyzing the ICT outsourcing industry's potential in Malaysia. This is an emerging industry that Malaysian companies can focus on by leveraging on thier strengths and avoiding the threats within the overall ICT outsourcing foray. The lack of studies and the potential of this industry in Malaysia, motivate the authors to write about this topic. Our findings suggests that, Malaysia has the strength of becoming world player in ICT outsourcing because sufficient infrastructure, strategic position of Malaysia and English language is widely spoken. These are the plus points of Malaysia to further excel as the provider of ICT outsourcing. On the other hand, the weaknesses that need to overcome is the low level of ereadiness in the world ranking. Political will and links with Middle East, China and India are the opportunities for Malaysia to laverage on its strength. However, Malaysia also need to avoid the threats such as slowly loosing competitive edge to lower cost producers namely Vietnam and China. Finally, our paper concludes with some options to enhance the capabilities of Malaysia as ICT outsourcing provider.
\end{abstract}

\section{INTRODUCTION}<smiles>CCC1CCCCC1C</smiles>

CT outsourcing is changing the way business is managed and operated world over. Outsourcing is a concept of contracting out part of the organization's business process to a third party that has the specific skills and services. It enables the organization to focus on their core competencies and manage resources efficiently. The rethinking of business strategies to develop and exploit core competencies, set the outsourcing bandwagon rolling. When considering a large and rapidly developing industry, such as the ICT industry, outsourcing exert huge potential business market. While India \& China are the leading ICT outsourcing providers in Asia, Malaysia has followed quickly, especially in the area of customer support/call center and back-office processes. This is revealed by AT Kearney's study which ranked Malaysia third globally as an outsourcing hub in the year 2004. (A.T.Kearney, 2004)

Since Malaysia is in the third rank in the world for ICT outsourcing, it is appropriate to study ICT outsourcing as a strategic decision for offshore as well as local companies. A.T.Kearney also reports that companies continue to make outsourcing decisions that are driven by cost reduction and the desire to focus on their core operations, rather than pursue outsourcing in an effort to drive more revenue and seize competitive advantage (A.T.Kearney, 2004). The role of outsourcing in terms of long-term strategic implication, need to be dealt with in 
detail. Therefore, we propose to use a SWOT framework to achieve the study objectives and to analyze the extent of ICT outsourcing in Malaysia. SWOT analysis is an analysis based on strategic management principles, examining the strengths, weaknesses of a company internally, 'vis a vis' its opportunities and threats, externally, in terms of strategic decisions of ICT outsourcing practices.

No significant study has been carried out on analyzing the ICT outsourcing industry's potential in Malaysia. This is an emerging industry that Malaysian companies can focus on by leveraging on their strengths and avoiding the threats within the overall ICT outsourcing foray. The lack of studies and the potential of this industry in Malaysia, motivate the authors to write about this topic.

The objectives of this paper are:

1. to review the extent of ICT outsourcing in Malaysia

2. to examine of all current and potential strengths, weaknesses, opportunities and threat with reference to ICT outsoucing in Malaysia.

3. to identify possible future strategic options for ICT outsourcing in Malaysia.

This paper proceeds as follows. First the relevance of this research to the study objectives is examined. This includes an overview of the outsourcing practices in general, specifically ICT outsourcing experience in Malaysia and considerations relevant to outsourcing decisions. Section 3 presents the purpose of this study which will describe the significance of the study to ICT outsourcing practices through a SWOT analysis. This is followed by success factors influencing ICT outsourcing in Malaysia. Section 5 highlights the future of ICT outsourcing in Malaysia. The paper concludes with the researchers' review on the overall ICT outsourcing industry in Malaysia.

\section{LITERATURE REVIEW}

\section{ICT Outsourcing Practices In Malaysia}

As with most developing countries, there are limited empirical studies conducted to evaluate the extent of IS/ICT outsourcing in Malaysia. However, a few large companies are embarking on ICT outsourcing projects, and the Malaysian government too is outsourcing most of the important national projects such as the Smart School, Human Resource Management Information Systems, and e- procurement project (M.A. Suhaimi, 2005).

According to Deloitte survey, Malaysia has the potential to be an attractive global player as an ICT outsourcing provider because of her stable economic growth, friendly business driven environment, continuous improvement in infrastructure, affordable infrastructure and good fiscal, tax, and regulatory environment.[5] Malaysia is a location of choice for multinationals because it uniquely possesses all desirable qualities sought by service providers, world-class infrastructure and a highly-skilled talent pool and competitive costs.(MDC, 2006)

Malaysia has the capacity to provide the environment through Multimedia Super corridor (MSC). Through MSC, Malaysia is highlighted to the world as an ideal choice and hub for information technology and Shared Services and Outsourcing (MDC, 2006). MSC focuses on infrastructure for knowledge development and it expects to create 10 thousand to 100 thousand highly skilled human capitals by the year 2020. Out of this, 30-40\% people will involve in outsourcing. (Farazira, 2005)

Malaysia views outsourcing as a value-added service to generate revenues and also as a mechanism to improve IT performance (M.A. Suhaimi, 2005). Many organizations in Malaysia such as Scicom (MSC) Berhad, CSC and its affiliates CSA Malaysia, EA Consulting Asia Pacific Sdn Bhd, IBM, Vsource Asia Berhad, REDwire Global Solution, Xpertsys Solutions Sdn Bhd, Marvelsoft, Golden Dragon Information System, Mc Dees Consulting and ShreeSoft Sdn Bhd are offshore ICT outsourcing providers to customers in Asia Pacific, US and UK. Scicom in one of the largest contact centre service provider in Business Brocess Outsourcing (BPO) in the country. Scicom has in recent times, been showcased for the country's fledging outsourcing industry. Today, Scicom provides BPO services 
to companies such as Nokia in Malaysia and services the mobile phone giants in India through its Bangalore-based operations. (Singam, 2006)

The outsourcing industry is expected to grow at $8.0 \%$ in 2003-2006 in the call centre operations and higher value-added processes such as analytical and research processes and procurement and supply chain management. IDC predicts that ICT outsourcing market will grow to $\$ 350$ milion in 2008. Outsourcing by Malaysia companies will rise to growth rate $27.2 \%$ over next 5 years. (Lee, 2004)

\section{Considerations Relevant To Outsourcing Decisions}

According to Tan Say Leong, business development director, CSA Malaysia, organizations today consider outsourcing and out tasking services for several reasons. Chief among them are the need to focus on the core business and redirect their resources to manage mission critical IT systems. "Outsourcing can help address some of these issues by relieving the workload on internal IT resources. It can free internal IT resources to focus on the main systems and improve their performance in other more mission critical areas," he said (Computerworld, 2005). John Ward in his book "Strategic Planning for Information Systems", argues that the decision on sourcing should be made on the future contribution of applications, as well as the current cost of IT resources and technology. (John Ward, 2000)

\section{Strength, Weaknesses, Opportunities And Threat (SWOT)}

The need to understand and develop a fit between ICT outsourcing and business strategy has long been emphasized by researchers and practitioners (M.A. Suhaimi, 2005). Study finds most companies fail to think strategically about outsourcing. Majority make outsourcing decisions based on cost-reduction, operational goals, enhance services and to focus on core business but very few companies make the decision based on revenue growth strategy. Since ICT business is now getting more and more complex, the need to analyze ICT outsourcing in terms of its strength, weaknesses, opportunity and threat becomes more vital.

\section{METHODOLOGY}

This paper is written based on analysis of secondary data. This is given the fact that the researchers are using the paper as a basis to support their on-going work in this area. The main sources of references are from AT Kearney's report entitled Making Offshore Decisions by A.T Kearney, a global management consultancy firm, which says that Malaysia is "the natural choice for offshore services", a paper called MSC A Significant Player In Shared Services And Outsourcing (SSO) presented in National Association of Software and Service Companies (NASSCOM) Forum and Seddon's Does Domberger's theory of the contracting organization explain satisfaction with IT outsourcing? From Twenty-Third International Conference on Information Systems.

\section{PURPOSE}

Given this backdrop, the purpose of this paper is to develop strength, weaknesses, opportunity and threats in the context of ICT outsourcing in Malaysia. The paper will also draw out a list of strategies to enhance capabilities of ICT outsourcing in Malaysia.

\section{SWOT Analysis}

Figure 1 provides a summary of the Strength, Weakness, Opportunity and Threats framework for ICT outsourcing in the context of Malaysia. 


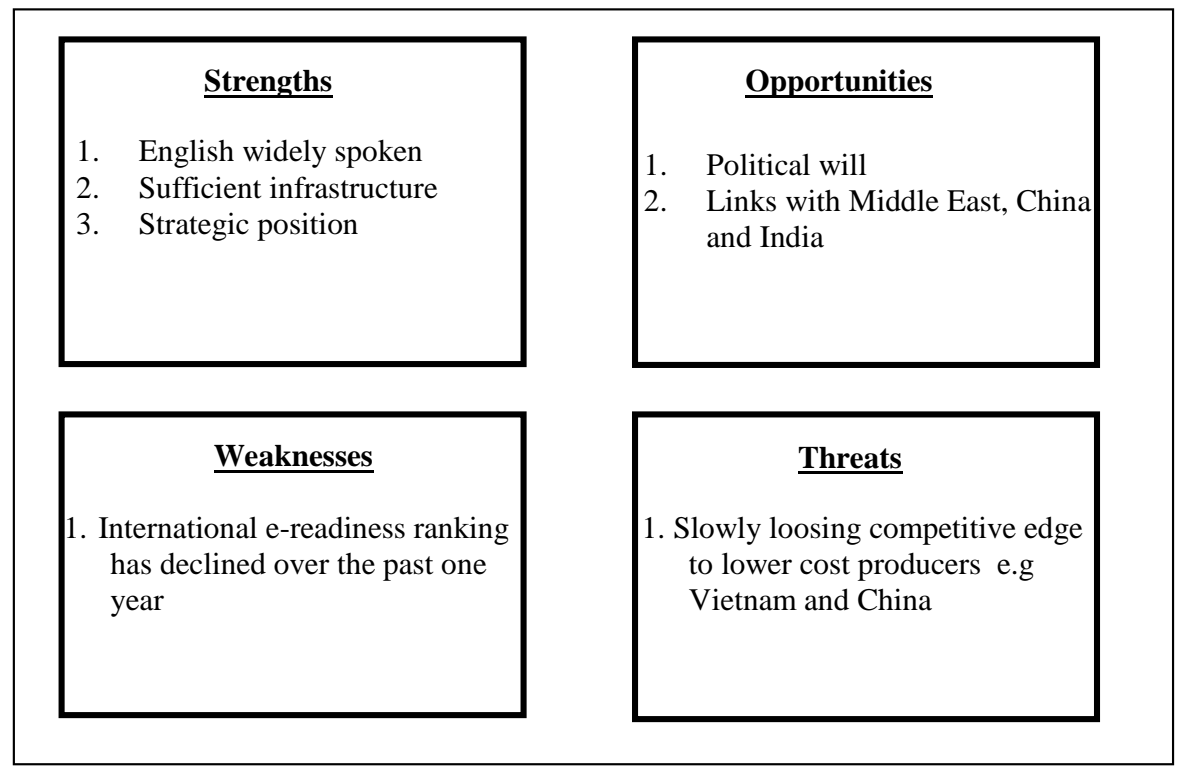

Figure 1 : Strengths, Weaknesses, Opportunities and Threats Framework for Malaysia

Strength. Malaysia was formally a colony of the British Empire. She gained her independence in the year 1957. Although Bahasa Melayu is the national language, English is the main medium of communication between the various ethnic groups in Malaysia. Furthermore, English is the main medium of communication within the business and corporate sector in Malaysia. This is arguably the main compelling factor for using Malaysia as an ICT outsourcing haven. The country is well developed in terms of its infrastructure, boasting several major International landmarks such as the Kuala Lumpur Petronas Twin Towers and the Kuala Lumpur International Airport (KLIA). In fact Malaysia is leading several road and other infrastructure projects in other nations such as India, Africa, and Middle East. Malaysia is also strategically located in the global map-she lies in the heart of South East Asia, closely positioned to Singapore (South), Thailand (North), and China (North East). Collectively, these forces drive Malaysia's competitiveness as a potential ICT outsourcing hub in the eyes of the world.

Weaknesses. Nevertheless, despite its strategic strengths as outlined above, the attractiveness of Malaysia in the context of E-business and E-Commerce application development and utilization remains questionable. In 2004, Malaysia was positioned no. 33 in terms of its global e-readiness index (Economist Intelligence Unit, 2005). However, in mere one years, this ranking declined marginally - today, she is positioned $35^{\text {th }}$ in the world in terms of being eready.

Opportunity. However, this does not mean that Malaysia does not have anything to offer as an outsourcing haven. The opportunities are there. There is strong political will in making Malaysia the ICT hub in Asia. In 1996, the then Prime Minister Tun Mahathir Mohammed spear headed the 15 by 50 miles Multimedia Super Corridor initiative. The MSC is touted as Malaysia's gift to the ICT world. Numerous ICT multinational giants have stamped their support and operations within the Corridor. The incumbent Premier, Abdullah Ahmad Badawi and his cabinet remains committed to this hallmark project in Malaysia. Initiatives to attract investment into Malaysia within the realms of ICT outsourcing are currently underway and parked within the macro objectives of the MSC.

Malaysia has significant recognition from world leaders as a moderate and modern Islamic country. She is well represented in the Organization for Islamic Countries (OIC). She is well linked to the Middle East market. This offers a viable opportunity for countries that intend to use Malaysia as an ICT outsourcing hub, and use the products and services generated to capture the Middle Eastern market. In addition, Malaysia also has significant roots and ties with both China and India, the two power-houses for the IT industry in the future. 
Threats. The main threats for Malaysia as an outsourcing haven mainly comes from the fact that she is loosing her competitiveness as a low-cost, low-wage producer. Malaysia is increasingly facing the threat from lower cost producers within the region. These include nations such as Thailand, Myanmar, Indonesia, and China.

\section{SUCCESS FACTORS TO OUTSOURCING}

The success of ICT outsourcing depends on global challenge. In simplest sense, the international challenge faced by Malaysia business is twofold:

1. how to gain and maintain the status as attractive offshore provider to other nations

2. how to defend domestic markets against seeking offshore provider's services.

However, at the micro level, there are a few options that may enhance the strength and exploit the opportunities by tackling its weaknesses and avoiding the threats in ICT outsourcing.

\section{Options To Enhance The Capabilities}

1. Provide tailor made courses in programming and computer languages.

The schools should act as a sort of one-stop-shop when the aspiring students can get introduced to modern and superior programs and languages at competitive prices.

2. Increase the presence and proximity of outsourcing vendors' offices.

This can improve control and co-ordination with the vendor. It can also serve as a marketing hub.

3. Interlace infrastructure, security, transparency, innovation and skills.

All these pieces must be properly interlaced to ensure e-readiness and to attract the share of the world's technology-earmarked foreign investment.

4. Incorporate ICT as a compulsory subject in education system.

Currently ICT stands as a subject based on individuals' preference and financial strength. The study of ICT is only pursued after the upper secondary level if the student wish to secure career in ICT stream. The national education system should incorporate this subject as one of the core subject just like Bahasa Malaysia, Mathematics and Science. Then, Malaysia will be able to produce even doctors or accountants who can write programs. Only then, the level of IT literacy will increase and hence increase the highly skilled labor pool for the purpose of ICT outsourcing industry growth.

5. Inculcate service culture in local companies.

Customer services must be high on local companies list of priorities. Leo Ariyanayakam, Scicom's CEO pointed out that as Malaysia gets de-regulated and new regulations come about and consumer awareness increases, more and more companies will come to realize the need for a service-oriented culture. "When that happens, we will be well-placed to move in.”. (Singam, 2006)

\section{FUTURE OF ICT OUTSOURCING IN MALAYSIA}

More and more companies around the world are welcoming ICT outsourcing. As a result, Asia Pacific countries have become market leaders in ICT outsourcing industry. Although India and China offering attractive cost advantage and large educated labor pool, Malaysia too is considered equally attractive in terms of having strong score in stable economic growth, continuous and improved infrastructure, friendly business driven environment, affordable 
infrastructure and proper fiscal, tax and regulatory environment (Farazira, 2005). The success of Malaysia in becoming an ICT outsourcing hub is assured only if Malaysia can produce more highly skilled labor pool to support the demand of ICT outsourcing from the rest of the world. In addition significant support from the incumbant government and leadership are needed to stimulate Malaysia’s attrractiveness as a outsourcing hub.

\section{CONCLUSION}

SWOT analysis can play an important role to assess Malaysia of becoming world player in ICT outsourcing. The result of SWOT analysis on ICT outsourcing industry indicates that Malaysia has all the potential to further expand its portfolio of ICT solutions: sufficient infrastructure, strategic position, English widely spoken, political will and links with Middle East, China and India. However, weaknesses and threats are also revealed by this study: decline in international e-readiness ranking and loosing competitive edge to lower cost producers such as Vietnam and China. These constraints essentially need to be tackled in order to tap more opportunities in the areas of ICT outsourcing. The study highlighted a few options to enhance the capabilities of ICT outsourcing: provide tailor made courses in programming and computer languages, increase the presence and proximity of outsourcing vendors' offices, interlace infrastructure, security, transparency, innovation and skills, incorporate ICT as a compulsory subject in education system and inculcate service culture in local companies.

\section{REFERENCE}

1. A.T Kearney's, (2004) Making Offshore Decisions, Location attractiveness index. [online], [Accessed on 2nd February 2006]. Available for World Wide Web: www.atkearney.com.

2. Angelina, P. Malaysia must move or lose outsourcing opportunity. [online]. [Accessed on 27 $7^{\text {th }}$ January 2006]. The Star Online. Available form World Wide Web: www.thestar.com.

3. Computerworld Malaysia (2005) Weighing the outsourcing option. [online]. [Accessed on 15th January 2006]. News Forum, Available from World Wide Web: www.computerworld.com.my.

4. Computerworld Malaysia (2003) Malaysia: Success comes one part at a time. [online]. [Accessed on 27th January 2006]. Available from World Wide Web: www.computerworld.com.my.

5. $\quad$ Economist Intelligence Unit (2005) 2005 e-readiness rankings [online]. [Accessed on $6^{\text {th }}$ Mar 2006]. Available from World Wide Web : http://www.eiu.com/site info.asp?info_name=eiu_2005 e readiness_rankings,

6. Farazira A.Y (2005) Malaysia aims to join the tops in outsourcing industry [online]. [Accessed on $15^{\text {th }}$ Jan 2006]. Available from World Wide Web: www.bernama.com.my .

7. Lacity, Mary Cecelia. Willcocks, Leslie P. (2000). Survey of IT outsourcing experiences in US and UK Organizations. Journal of Global Information System. Volume Apr-June 2000, page 5.

8. Lee, Cordelia (2004) Outsourcing picks up in Malaysia [online]. [Accessed on 15 ${ }^{\text {th }}$ January 2006]. Available from World Wide Web: www.news.com.

9. Multimedia Development Corporation (MDC) (2006) MSC A Significant Player In Shared Services And Outsourcing (SSO), National Association of Software and Service Companies (NASSCOM) Forum. [online], [Accessed on $11^{\text {th }}$ February 2006], Available from World Wide Web: www.mdc.com.my.

10. Nair, K.G.K., Prasad P.N. (2004) Offshore outsourcing: A SWOT analysis of a state in India. Information System Management. Summer 2004. Volume (21,3), page 34.

11. Seddon, Peter B. Cullen, Sara. Willcocks, Leslie P. (2002). Does Domberger's theory of the contracting organization explain satisfaction with IT outsourcing?. Twenty-Third International Conference on Information Systems.

12. Singam, Sheila. (2006). Finding a niche. Options. 27 February 2006. TheEdge Communications Sdn Bhd, Malaysia.

13. Suhaimi M.A, Mustaffa, M.S. and Hussin, H (2005) IT outsourcing as an innovative strategy: the experience of a Malaysian bank. In: The Second International Conference on Innovations in Information Technology (IIT’05), IIUM, Malaysia.

14. Ward, John. Griffiths, John. (2000). Strategic Planning for Information System. $2^{\text {nd }}$ Edition, John Wiley \& Sons, England. 